\title{
Review of Digitalized Patient Education in Cardiology: A Future Ahead?
}

\author{
Marinka D. Oudkerk Pool ${ }^{a}$ b Jean-Luc Q. Hooglugt ${ }^{a}$ Marlies P. Schijven ${ }^{c}$ \\ Barbara J.M. Mulder ${ }^{a}$ Berto J. Bouma ${ }^{a}$ Robbert J. de Winter ${ }^{a}$ Yigal Pinto $^{a}$ \\ Michiel M. Winter ${ }^{\mathrm{a}}$ \\ aDepartment of Cardiology, Amsterdam UMC, University of Amsterdam, Amsterdam, The Netherlands; \\ ${ }^{b}$ Netherlands Heart Institute, Utrecht, The Netherlands; ' ${ }^{C}$ Department of Surgery, Amsterdam UMC, University of \\ Amsterdam, Amsterdam, The Netherlands
}

\section{Key Words}

Patient education · Phone application · Web-based · Video · Virtual reality

\begin{abstract}
Introduction: An increased focus on shared decision-making and patient empowerment in cardiology and on patient outcomes such as quality of life (QoL), depression, and anxiety underline the importance of high-quality patient education. Studies focusing on digital means of patient education performed in other disciplines of medicine demonstrated its positive effect in these areas. Therefore, a review of the current literature was performed to (i) evaluate the status of innovative, digitalized means of patient education in cardiology and (ii) assess the impact of digital patient education on outcome parameters (i.e., patient knowledge (or health literacy), QoL, depression, anxiety, and patient satisfaction). Method: A review of the current literature was performed to evaluate the effect of digitalized patient education for any purpose in the field of cardiology. Medline and EMBASE were searched for articles reporting any digital educational platform used for patient education up to May 2020. The articles were compared on their effect on patient knowledge or health literacy, QoL, depression or anxiety, and patient satisfaction. Results: The initial search yielded 279 articles, 34 of
\end{abstract}

karger@karger.com www.karger.com/crd

Karger"

GOPEN ACCESS
(C) 2021 The Author(s)

Published by S. Karger AG, Basel

This is an Open Access article licensed under the Creative Commons Attribution-NonCommercial-4.0 International License (CC BY-NC) (http://www.karger.com/Services/OpenAccessLicense), applicable to the online version of the article only. Usage and distribution for commercial purposes requires written permission. which were retained after applying in, and exclusion criteria. After full-text analysis, the total number of articles remaining was 16. Of these, 6 articles discussed the use of smartphone or tablet applications as a means of patient education, whereas 3 reviewed web-based content, and 7 evaluated the use of video ( 2 three-dimensional videos, from which one on a virtual reality headset). Conclusion: This review demonstrates that digital patient education increases patient knowledge. Overall, digital education increases QoL and lowers feelings of depression and anxiety. The majority of patients express satisfaction with digital platforms. It remains important that developers of digital patient education platforms remain focused on clear, structured, and comprehensible information presentation.

(C) 2021 The Author(s)

Published by S. Karger AG, Basel

\section{Introduction}

Patient education is gaining importance due to an increased focus on shared decision-making and patient empowerment in cardiology. Patient outcome metrics such as quality of life (QoL), therapy adherence, depression, or

Marinka D. Oudkerk Pool and Jean-Luc Q. Hooglugt contributed equally. 
anxiety are influenced by patient education [1]. Previous research demonstrates potential improvements in patient education based on "demand-matched" education, that is, the individualization of content, the use of combined media, and more patient-centered information [1-3]. Although the importance of adequate patient education is known and several methods to improve education have been explored, the current approach remains insufficient to fulfill the expectations and demands of patients and cardiologists [4]. Whereas a mere $16 \%$ of patients were able to explain the benefits of a procedure after a standard care preprocedural consultation, $40 \%$ could do so after watching an informative video [5]. This hiatus in patient knowledge could cause anxiety and depression, with subsequent loss of QoL.

The involvement of digitalized education modalities such as smartphone applications, videos (three-dimensional [3D]), web-based content, or virtual reality (VR) is increasingly embraced in patient education in many disciplines of medicine [6-8]. These modalities include the latest innovations in the field of digital media such as $3 \mathrm{D}$ videos or $\mathrm{VR}$, which may provide new dimensions for patient education. The use of immersive patient education formats that align with the patient's situational and environmental expectations in a preoperative setting appears to be an effective tool to alleviate anxiety [9]. Furthermore, the availability of useful and well-presented preprocedural information in printed, video, and/or VR may contribute to additional anxiety reduction [10-13].

Limited research has been performed to evaluate the technology readiness and effectiveness of these innovative means of patient education in cardiology. The field of cardiology could leverage these technologies to increase patient empowerment and QoL, therapy adherence, and decrease patient depression or anxiety [1-3]. Therefore, the aims of this review are 2-fold: (i) evaluating the status of digital patient education in cardiology and (ii) assessing the impact of digital patient education on outcome measures like patient knowledge or health literacy, QoL, anxiety or depression, and patient satisfaction.

\section{Methods}

\section{Literature Search}

Both Medline and EMBASE were used to search the published literature for studies up to May 6, 2020. The search was developed iteratively for synonyms of "cardiology" and "patient education," which could be combined with "animation," "augmented reality," "brochures," “digital," "digitalized," “educational video," “infor- mation," "immersive," "serious game," "telerehabilitation," "video," "virtual reality," or "website," in both controlled vocabulary (i.e., MeSH) and free text words. Nonhuman studies, reviews, studies not focused on cardiology, studies not focused on digital platforms of patient education, or non-English articles were excluded. The reference list and cited articles were checked for additional articles.

\section{Selection of Studies}

Studies were included if they applied a digital format for patients to learn more about their disease or an upcoming procedure (i.e., smartphone or tablet application, video, web-based content, or VR). Screening, eligibility, and inclusion were performed in full by 2 authors (M.O.P. and J.H.). Disagreements concerning eligibility were resolved by discussion.

\section{Extraction of Data}

The extracted data from each article were author, publication year, study design, used modality, patient population, protocol, outcome, result on health literacy or patient knowledge, QoL, depression or anxiety, patient satisfaction, the number of patients, and if applicable, the amount of patients in the intervention and control groups. The studies were categorized into 3 outcome categories: patient knowledge (also known as health literacy), QoL, depression or anxiety, and patient satisfaction.

\section{Results}

\section{Search Result}

During screening, 268 articles were selected based on title and abstract. Figure 1 shows the flowchart for the article selection. 234 articles were excluded because they (i) did not provide a digital way of patient education, (ii) were not based on cardiology, (iii) were review articles or case-reports, (iv) focused on healthcare professionals instead of patients, or (v) were not written in the English language. Thirty-four articles were read in full, after which another 18 articles were excluded; 5 focused on training nurses in patient communication, 2 focused on telemonitoring, another 2 focused on exercise training, and 9 were merely descriptive and did not include patient evaluation. The final analysis consisted of 15 articles and 1 abstract (Fig. 1). Figure 2 shows a heatmap of the found articles by digital platform and evaluated outcome metrics. The bigger the circle, the more articles were found on the platform with corresponding outcome measure. A green circle indicates a positive effect, while a grey circle indicates no significant change. The light blue background color indicates sparse research in the domain, while dark blue indicates dense research in the domain. 
Fig. 1. Flow diagram of search query.

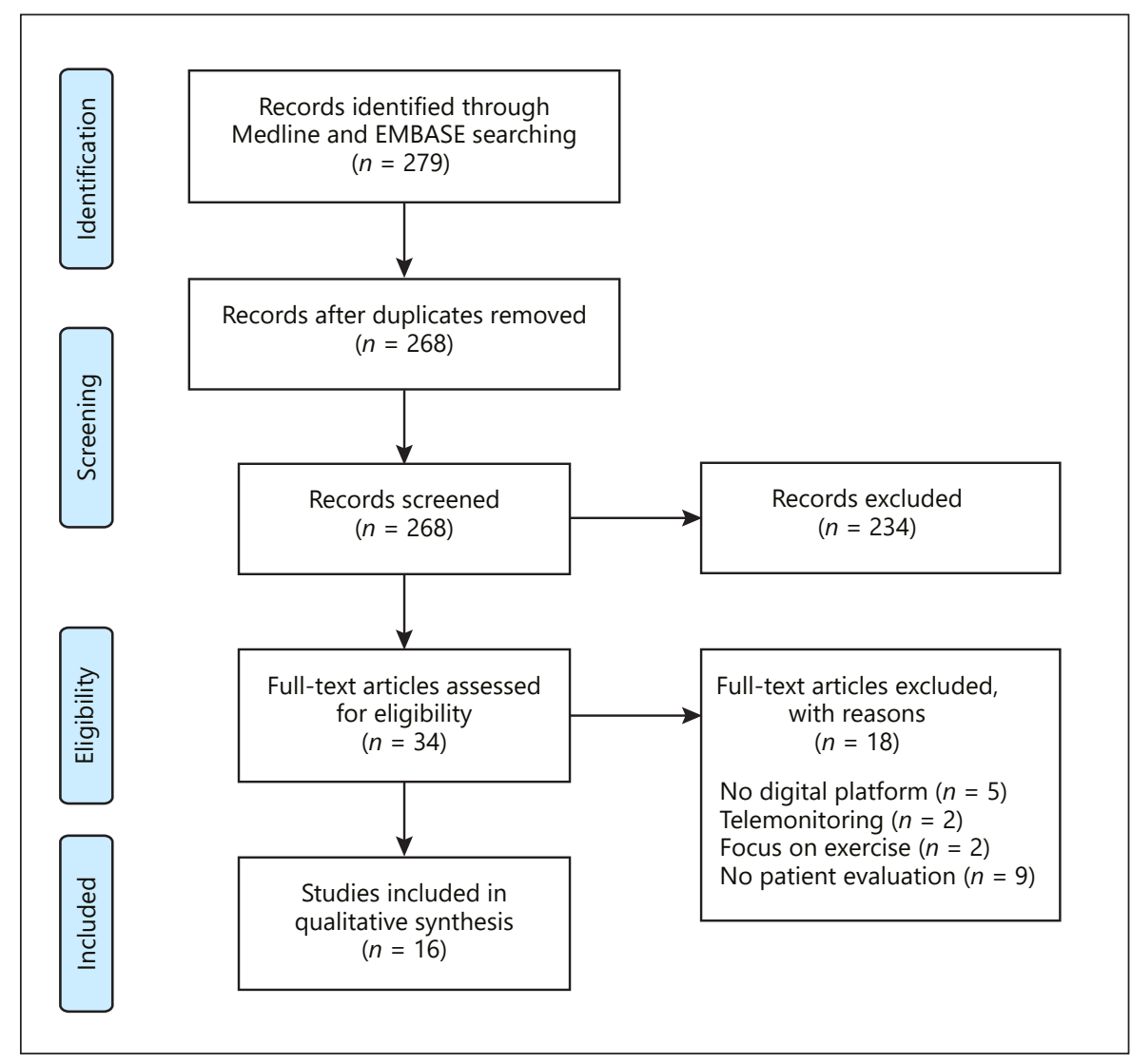

\section{Patient Population}

In total, 2,481 adult patients $(59.5 \%$ male; mean age $64.8 \pm 7.6$ years) were analyzed. In 106 patients, the gender was not described, nor was the exact age in 536 patients (all over 18 years old). Nine articles divided their population into a control group ( 845 patients, $34 \%$ of the total patient population) and an intervention group (815 patients, $33 \%$ of the total patient population).

\section{Patient Education Methods}

Six papers focused on the use of smartphone or tablet applications on patients with coronary artery disease (1), heart failure (3), diagnostic catheterization (1), or heart patients in general (1). Three papers evaluated the use of a web-based environment on patients with congenital heart disease (1), coronary angiography (1), and heart failure (1). Another 7 papers focused on (3D) video education in preprocedural setting for coronary angiography (3), electrophysiology (1), or catheterization (2). Last, 1 paper evaluated the use of a $3 \mathrm{D}$ video in a VR headset on patients suffering from atrial fibrillation. An overview of the selected articles, their used modality, protocol, outcome, effect on patient knowledge, QoL, depression or

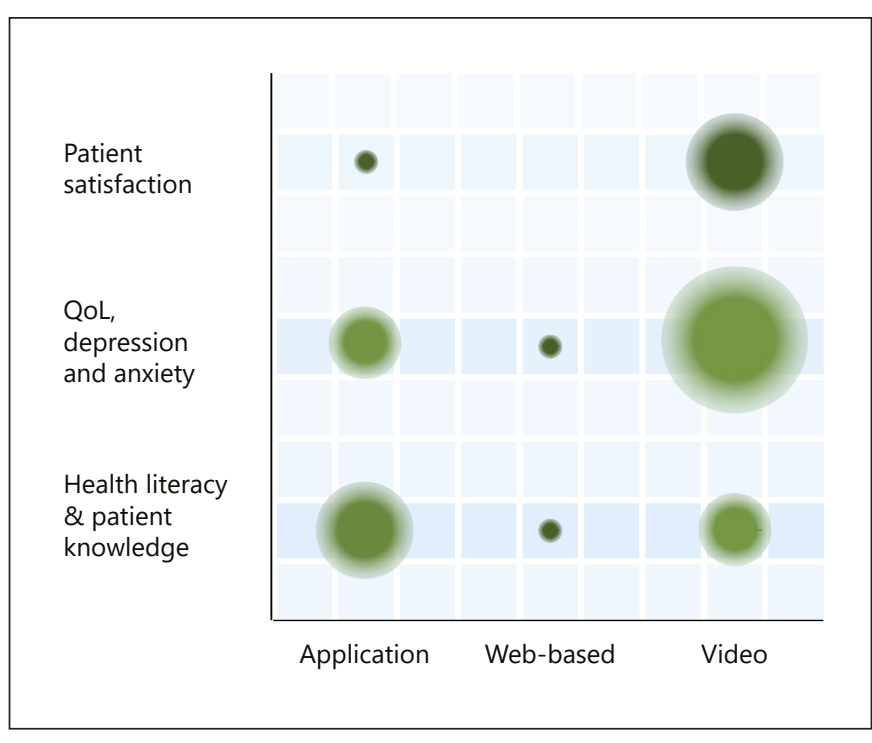

Fig. 2. Heatmap of the found articles by digital platform and evaluated outcome metrics. The bigger the circle, the more articles were found on the platform with corresponding outcome measure. A green circle indicates a positive effect, while a grey circle indicates no significant change. The light blue background color indicates sparse research in the domain, while dark blue indicates dense research in the domain. 
anxiety, patient satisfaction, and the division in control and intervention group is shown in Table 1.

The majority of papers focused either on a smartphone or tablet application or on video (6 papers about smartphone or tablet application and 7 about video). Three of the 6 papers focusing on smartphone applications used a control group to test their application. Hägglund et al. [14] compared their tablet software with standard care on patients suffering from heart failure. Melin et al. [15] focused exclusively on patients with heart failure and divided their population into a control group receiving standard care, and an intervention group receiving a tablet computer with connection to a weighing scale and information on how to improve life with heart failure. Tait et al. [16] divided their population into either standard care or an intervention with an interactive tablet computer-based information program on which they received information about their heart, condition, and procedure. In the video education, all 6 papers compared patients watching the video to standard care. Goldberger et al. [17] and Gökçe and Arslan [18] performed divided patients into groups receiving written, oral, or video information with the exact same content in each group. Lattuca et al. [19], Herrmann and Kreuzer [10], and Gökçe and Arslan [18] focused on coronary angiography, Ruffinengo et al. [20] and Torrano et al. [5] applied their video for catheterization, and Goldberger et al. [17] evaluated the video on diagnostic electrophysiology. Only Doll et al. [21] compared their webbased education about coronary angiography on a control group. The remaining 6 studies did not compare the effects of visualized patient information to a control group but measured the effect of their modality on heart patients.

\section{Result of Used Modality on Patient Knowledge, QoL,} Depression, Anxiety, or Patient Satisfaction

Smartphone or Tablet Application

Six articles evaluated the use of a smartphone or tablet application, from which 4 measured the possible increase of patient knowledge, 2 measured the QoL, depression, or anxiety, and 3 evaluated patient satisfaction. Hägglund et al. [14] showed a statistically nonsignificant improvement in patient knowledge, as their control and intervention groups did not differ significantly enough. Melin et al. [15], Strömberg et al. [22], and Tait et al. [16] used an application on either a smartphone or tablet to increase patient knowledge. Melin et al.'s [15] study found that after 6-month follow-up patients displayed better self-care and better engagement during consulta- tion sessions. Tait et al.'s [16] study found that patients using the tablet computer had significantly better recall of the information compared to the group receiving written and verbal information. Strömberg et al.'s [22] study found that using a web-based content helped patients understand their own disease better. In terms of QoL, Melin et al. [15] found that after 6-month follow-up patients scored higher on the Kansas City Cardiomyopathy Questionnaire (72.7 in the intervention group vs. 51.8 in the control group) using a tablet application. Hägglund et al. [14] found a significant increase in QoL measured by means of the SF-36 questionnaire (65.1 vs. 52.1). Cho et al. [23] and Jain et al. [24] both evaluated an application and found that patients found the smartphone application useful. Strömberg et al. [22] found that patients were either satisfied or very satisfied using the web-based environment for gaining information about their disease.

\section{Web-Based Education}

Three papers discussed the use of web-based education, 2 measured patient knowledge, and 1 evaluated the QoL. Valente et al. [25] and Doll et al. [21] all used webbased content to increase patient knowledge. These authors found that using a web-based content helped patients understand their own disease better. Delgado et al. [26] showed an increase in QoL based on the Minnesota Living with Heart Failure Questionnaire after 3 months, but this effect was not statistically significant.

\section{Video-Based Education}

Seven articles evaluated the use of video-based content, from which 4 measured the possible increase of patient knowledge, 5 measured the QoL, depression, or anxiety, and 3 evaluated patient satisfaction. Torrano et al. [5] and Lattuca et al. [19] demonstrated that questions on planned procedures were better answered by the intervention group, compared to the control group (Torrano et al. [5]: $75 \pm 17$ vs. $32 \pm 19$; Lattuca et al. [19]: $12 \pm 3$ vs. $10 \pm 3$ ). Goldberger et al. [17] evaluated a short questionnaire to patients after their oral, written, or video information about their understanding of diagnostic electrophysiology but did not find a significant difference in patient knowledge between formats (patient scores $6 \pm 2$, $4 \pm 2$, and $5 \pm 2$, respectively). Their work was the sole publication that did not find an effect on QoL, depression or anxiety, and patient satisfaction before and after either of the 3 consent formats. Herrmann and Kreuzer [10], Ruffinengo et al. [20], and Gökçe and Arslan [18] all found a decrease in anxiety when showing a video to pa- 


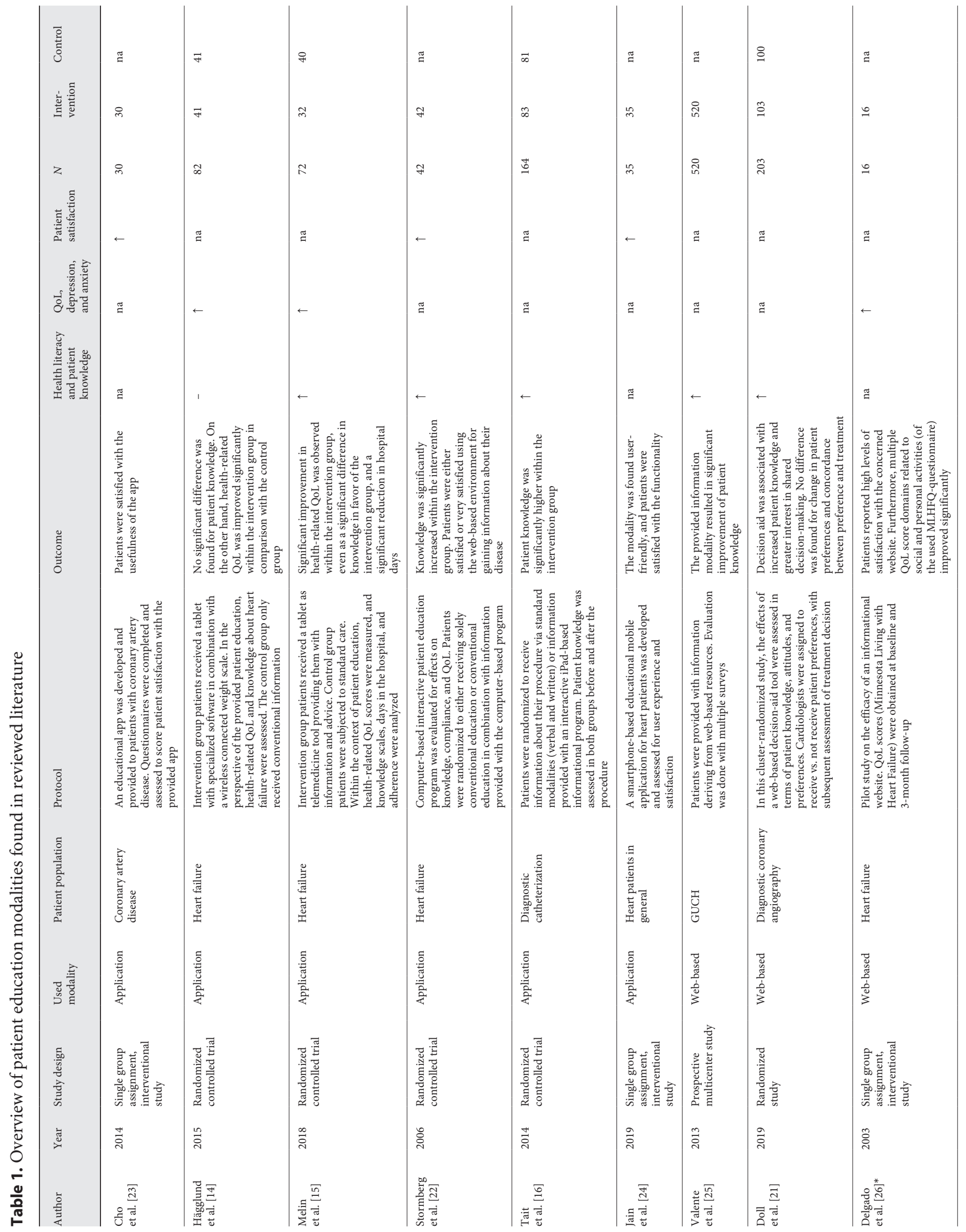




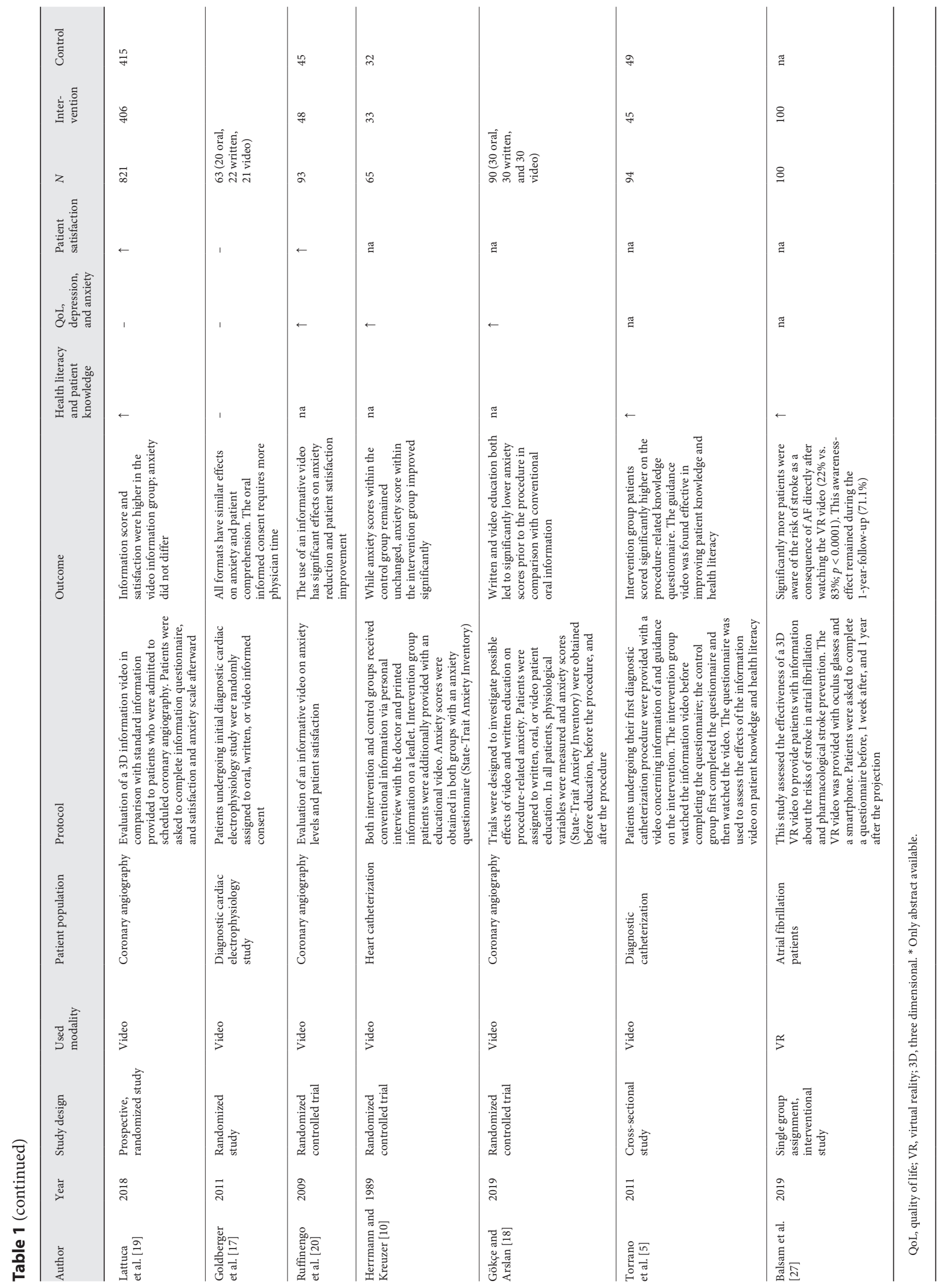


tients about their procedure. Lattuca et al. [19] found a statistically insignificant $(p=0.07)$ trend toward decrease in anxiety. In terms of patient satisfaction, the authors found that the self-reported satisfaction with the video format was higher than the standard care ( $8.4 \pm 1.9$ vs. 7.7 \pm 2.3 on a dedicated 16-point questionnaire). Ruffinengo et al. [20] found that the satisfaction level was significantly higher in patients receiving the video format compared to standard care on the visual analogue scale $(p=0.00001)$. Balsam et al. [27] was the only article to describe a VR video to educate patients. The education was focused on the disease itself, as well as on therapy and possible complications. They found that significantly more patients in the intervention group were aware of the risk of stroke as a consequence of atrial fibrillation, compared to the control group ( 83 vs. $22 \% ; p<0.0001$ ). This effect remained during the 1-year-follow-up period (71 vs. $23 \%$; $p<$ 0.0001).

\section{Discussion}

This review compares 3 digital patient educational platforms for patient knowledge, QoL, depression or anxiety, and patient satisfaction, within the field of cardiology. We found that 3 main platforms were used in this search, namely education video, smartphone or tablet application, and web-based information. One article is based on a 3D video on a VR headset, possibly due to the novelty of the platform. Overall, the authors demonstrated a positive effect on the primary outcomes of patient knowledge, QoL or anxiety, and patient satisfaction. Most articles evaluate at least one or more of these outcome measurements, which enables a direct comparison between papers.

Previous studies on digital patient education in other fields of medicine demonstrated that digital patient education improves patient knowledge, QoL, decreases depression and anxiety, and increase satisfaction. In orthopedics, a smartphone application was developed to educate patients in the first 4 weeks after total knee replacement. The application had a positive effect on QoL, self-care, and patient satisfaction [28]. In oncology, White et al. [29] found an increased QoL in women with breast cancer when evaluating an informationbased website. In dermatology, Migden et al. [30] evaluated that the use of video increased patient knowledge on how to properly perform wound care. Especially, information retention seemed to be drastically improved by digital patient education. We expected these positive results to hold similarly true for cardiology patient education.

The results of this review show 3 major digital platforms, namely smartphone or tablet application, webbased, and video content. Teaching patients via webbased content seems achievable since patients increasingly possess their own computers and smartphones [31]. Interactive media's such as an application or web-based content allow patients to choose their own areas of interest and can go over the material at their own pace, increasing interest in health literacy $[22,31]$. The biggest disadvantage to online videos is retaining attention when learners can only passively watch the videos. Creating interactivity expands the attention span, making patients adhere more to the information given [21, 22, 32]. Dror et al. [33] found that adding interactive elements such as questions prolong the students' attention span and increase the amount of information retained by the student. As with the video format, patients with low literacy skills seem to benefit greatly from web-based education. A possible explanation could be that learning from a computer is less stressful than in the hospital environment from a doctor or nurse. Patients may be embarrassed to ask questions they feel may expose a lack of knowledge on their part, which is not a problem in a web-based environment [22].

Goldberger et al. [17] did not find a statistically significant difference in anxiety or patient comprehension between oral, written, and video informed consent before their informational platform, immediately after consent, and after the intervention. They did find a difference in baseline scores between the 3 groups, meaning a suboptimal randomization. Anxiety scores before and directly after the consent procedure are comparable, which could be due to the short time between the questionnaires. Although they did not find a significant difference between the 3 consent procedures, they did show that written or video consent is just as effective as oral informed consent.

One article discussed the use of VR to educate patients with atrial fibrillation. By informing patients about their disease, patients showed to adhere more to their treatment [27]. Cleeren et al. [34] showed that 3D animations result in a higher patient knowledge when comparing to a drawn explanation of the same procedure. The use of $3 \mathrm{D}$ images or VR environment is similar to a video, but it may make the message even more explanatory due to increased interactivity. Pandrangi et al. [9] used VR as an active tool to teach patients preoperatively about abdominal aortic aneurysm. Patients felt better informed and 
more engaged because of the use of VR. Bekelis et al. [35] divided patients undergoing cranial and spinal operations in VR or standard care. Patients watching VR experienced less preoperative stress and were more satisfied. Jimenez et al. [36] also divided patients into the VR education or standard care and found that patients educated by VR had a higher knowledge about radiotherapy in breast cancer. VR seems to be a good way to educate patients before their procedure to reduce stress and gains a higher patient satisfaction. It also increases patient knowledge about their disease or therapy.

In this review, positive results were found in all outcome parameters. Digital education on any platform seems to especially help patients with low levels of education $[16,37-40]$. The use of applications by patients enhances understanding and recall of the given information when compared to standard care (written or oral) [16]. Possible explanations could be that patients can go through the information at their own pace, applications ask for active participation, and applications can visualize the heart or the procedure, making it comprehensible for patients [16, 37-39]. However, attention to an application is scarce due to an information-overloaded world [32]. Information should be given in a clear, and comprehensible way for patients to increase the amount of information to be recalled $[17,19,20]$.

Torrano et al.'s [5] study showed that only $16 \%$ of patients at baseline receiving standard care were able to explain the benefits of the procedure they were about to undergo. A changing world with increasingly available digital platforms should also change the manner in which doctors educate their patients. Smartphone or tablet application, web-based, and video education could contrib- ute in the way patient education is performed and may enhance patient knowledge, reduce anxiety, and seem to increase patient satisfaction.

\section{Conclusion}

Digital platforms show great potential in educating patients at their own pace, providing additional (visual) information, and are capable of describing the disease or procedure in a clear manner. Digital platforms are shown to increase patient knowledge and satisfaction. Overall, these platforms enhance QoL and decrease anxiety. It remains important for developers of digital information platform to focus on how to present their information in a clear, structured, and comprehensible way.

\section{Conflict of Interest Statement}

The funders had no role in the study design, data collection and analysis, decision to publish, or the preparation of the manuscript. The authors have no conflicts of interest.

\section{Funding Sources}

This research has been funded by the Dutch Heart Foundation under project number $2018 \mathrm{~T} 068$.

\section{Author Contributions}

All authors contributed to researching data, discussion of content, and reviewing and editing the manuscript before submission.

\section{References}

1 Fredericks S, Yau T. Clinical effectiveness of individual patient education in heart surgery patients: a systematic review and meta-analysis. Int J Nurs Stud. 2017;65:44-53.

2 Fredericks S, Beanlands H, Spalding K, Da Silva M. Effects of the characteristics of teaching on the outcomes of heart failure patient education interventions: a systematic review. Eur J Cardiovasc Nurs. 2010;9(1):30-7.

3 Boyde M, Turner C, Thompson DR, Stewart S. Educational interventions for patients with heart failure: a systematic review of randomized controlled trials. J Cardiovasc Nurs. 2011;26(4):E27-35.
4 Astin F, Stephenson J, Probyn J, Holt J, Marshall K, Conway D. Cardiologists' and patients' views about the informed consent process and their understanding of the anticipated treatment benefits of coronary angioplasty: a survey study. Eur J Cardiovasc Nurs. 2020; 19(3):260-8.

5 Torrano SK, Veiga VB, Goldmeier S, Azzolin K. Explanatory digital video disc with patients undergoing diagnostic cardiac catheterization. Rev Lat Am Enfermagem. 2011;19(4): 888-93.

6 Freeman D, Reeve S, Robinson A, Ehlers A, Clark D, Spanlang B, et al. Virtual reality in the assessment, understanding, and treatment of mental health disorders. Psychol Med. 2017;47(14):2393-400.
7 Thapa N, Park HJ, Yang JG, Son H, Jang M, Lee J, et al. The effect of a virtual reality-based intervention program on cognition in older adults with mild cognitive impairment: a randomized control trial. J Clin Med. 2020;9(5): 1283.

8 Johnson K, Liszewski B, Dawdy K, Lai Y, McGuffin M. Learning in 360 degrees: a pilot study on the use of virtual reality for radiation therapy patient education. J Med Imaging Radiat Sci. 2020;51(2):221-6.

9 Pandrangi VC, Gaston B, Appelbaum NP, Albuquerque FC, Levy MM, Larson RA. The application of virtual reality in patient education. Ann Vasc Surg. 2019;59:184-9. 
10 Herrmann KS, Kreuzer H. A randomized prospective study on anxiety reduction by preparatory disclosure with and without video film show about a planned heart catheterization. Eur Heart J. 1989;10(8):753-7.

11 Bondy LR, Sims N, Schroeder DR, Offord KP, Narr BJ. The effect of anesthetic patient education on preoperative patient anxiety. Reg Anesth Pain Med. 1999;24(2):158-64.

12 Tou S, Tou W, Mah D, Karatassas A, Hewett P. Effect of preoperative two-dimensional animation information on perioperative anxiety and knowledge retention in patients undergoing bowel surgery: a randomized pilot study. Colorectal Dis. 2013;15(5):e256-65.

13 Yang J-H, Ryu JJ, Nam E, Lee H-S, Lee JK. Effects of preoperative virtual reality magnetic resonance imaging on preoperative anxiety in patients undergoing arthroscopic knee surgery: a randomized controlled study. Arthroscopy. 2019;35(8):2394-9.

14 Hägglund E, Lyngå P, Frie F, Ullman B, Persson $\mathrm{H}$, Melin M, et al. Patient-centred homebased management of heart failure: findings from a randomised clinical trial evaluating a tablet computer for self-care, quality of life and effects on knowledge. Scand Cardiovasc J. 2015;49(4):193-9.

15 Melin M, Hägglund E, Ullman B, Persson H, Hagerman I. Effects of a tablet computer on self-care, quality of life, and knowledge: a randomized clinical trial. J Cardiovasc Nurs. 2018 Jul-Aug;33(4):336-43.

16 Tait AR, Voepel-Lewis T, Chetcuti SJ, Brennan-Martinez C, Levine R. Enhancing patient understanding of medical procedures: evaluation of an interactive multimedia program with in-line exercises. Int J Med Inform. 2014; 83(5):376-84.

17 Goldberger JJ, Kruse J, Kadish AH, Passman R, Bergner DW. Effect of informed consent format on patient anxiety, knowledge, and satisfaction. Am Heart J. 2011;162(4):780-e1.

18 Gökçe E, Arslan S. Possible effect of video and written education on anxiety of patients undergoing coronary angiography. J Perianesth Nurs. 2019;34(2):281-8.

19 Lattuca B, Barber-Chamoux N, Alos B, Sfaxi A, Mulliez A, Miton N, et al. Impact of video on the understanding and satisfaction of patients receiving informed consent before elec- tive inpatient coronary angiography: a randomized trial. Am Heart J. 2018;200:67-74.

20 Ruffinengo C, Versino E, Renga G. Effectiveness of an informative video on reducing anxiety levels in patients undergoing elective coronarography: an RCT. Eur J Cardiovasc Nurs. 2009;8(1):57-61.

21 Doll JA, Jones WS, Lokhnygina Y, Culpepper S, Parks RL, Calhoun C, et al. PREPARED study: a study of shared decision-making for coronary artery disease. Circ Cardiovasc Qual Outcomes. 2019;12(2):1-10.

22 Strömberg A, Ahlén H, Fridlund B, Dahlström U. Interactive education on CD-ROM: a new tool in the education of heart failure patients. Patient Educ Couns. 2002;46(1):7581.

23 Cho MJ, Sim JL, Hwang SY. Development of smartphone educational application for patients with coronary artery disease. Healthc Inform Res. 2014;20(2):117-24

24 Jain YS, Garg A, Jhamb DK, Jain P, Karar A. Preparing India to leverage power of mobile technology: development of a bilingual mobile health tool for heart patients. Cardiovasc $\mathrm{He}$ matol Agents Med Chem. 2019;17(2):125-34.

25 Valente AM, Landzberg MJ, Gianola A, Harmon AJ, Cook S, Ting JG, et al. Improving heart disease knowledge and research participation in adults with congenital heart disease (the health, education and access research trial: HEART-ACHD). Int J Cardiol. 2013; 168(4):3236-40.

26 Delgado DH, Costigan J, Wu R, Ross HJ. An interactive Internet site for the management of patients with congestive heart failure. Can J Cardiol. 2003;19(12):1381-5.

27 Balsam P, Borodzicz S, Malesa K, Puchta D, Tymińska A, Ozierański K, et al. OCULUS study: virtual reality-based education in daily clinical practice. Cardiol J. 2019;26(3):260-4.

28 Timmers T, Janssen L, van der Weegen W, Das D, Marijnissen WJ, Hannink G, et al. The effect of an app for day-to-day postoperative care education on patients with total knee replacement: randomized controlled trial. JMIR Mhealth Uhealth. 2019;7(10):e15323-16.

29 White V, Farrelly A, Pitcher M, Hill D. Does access to an information-based, breast cancer specific website help to reduce distress in young women with breast cancer? Results from a randomised trial. Eur J Cancer Care. 2018;27(6):1-14.

30 Migden M, Chavez-Frazier A, Nguyen T. The use of high definition video modules for delivery of informed consent and wound care education in the Mohs Surgery Unit. Semin Cutan Med Surg. 2008;27(1):89-93.

31 Melholt C, Joensson K, Spindler H, Hansen J, Andreasen JJ, Nielsen G, et al. Cardiac patients' experiences with a telerehabilitation web portal: Implications for eHealth literacy. Patient Educ Couns. 2018;101(5):854-61.

32 Geri N, Winer A, Zaks B. Challenging the sixminute myth of online video lectures: can interactivity expand the attention span of learners? OJKAM. 2017;5(1):101-11.

33 Dror I, Schmidt P, O'connor L. A cognitive perspective on technology enhanced learning in medical training: great opportunities, pitfalls and challenges. Med Teach. 2011;33(4): 291-6.

34 Cleeren G, Quirynen M, Ozcelik O, Teughels $\mathrm{W}$. Role of 3D animation in periodontal patient education: a randomized controlled trial. J Clin Periodontol. 2014;41(1):38-45.

35 Bekelis K, Calnan D, Simmons N, Mackenzie TA, Kakoulides G. Effect of an immersive preoperative virtual reality experience on patient reported outcomes: a randomized controlled trial. Ann Surg. 2017;265(6):1068-73.

36 Jimenez YA, Cumming S, Wang W, Stuart K, Thwaites DI, Lewis SJ. Patient education using virtual reality increases knowledge and positive experience for breast cancer patients undergoing radiation therapy. Support Care Cancer. 2018;26(8):2879-88.

37 Schrand T. Tapping into active learning and multiple intelligences with interactive multimedia: a low-threshold classroom approach. Coll Teach. 2008;56(2):78-84.

38 Luo G, Dong S, Wang K, Zuo W, Cao S, Zhang $\mathrm{H}$. Multi-views fusion CNN for left ventricular volumes estimation on cardiac MR images. IEEE Trans Biomed Eng. 2018 Sep;65(9): 1924-34.

39 Schank RC. Active learning through multimedia. IEEE Multime. 1994;1(1):69-78.

40 Rossi MJ, Guttmann D, MacLennan MJ, Lubowitz JH. Video informed consent improves knee arthroscopy patient comprehension. Arthroscopy. 2005;21(6):739-43. 